\title{
Xenobiotic metabolizing gene variants and renal cell cancer: a multicenter study
}

\author{
Julia E. Heck ${ }^{1,2}$, Lee E. Moore ${ }^{3}$, Yuan-Chin A. Lee ${ }^{1,2}$, James D. McKay ${ }^{1}$, Rayjean J. Hung ${ }^{4}$, Sara Karami ${ }^{3}$, \\ Valérie Gaborieau ${ }^{1}$, Neonila Szeszenia-Dabrowska ${ }^{5}$, David G. Zaridze ${ }^{6}$, Anush Mukeriya ${ }^{7}$, Dana Mates ${ }^{8}$, \\ Lenka Foretova ${ }^{9}$, Vladimir Janout ${ }^{10}$, Helena Kollárová ${ }^{10}$, Vladimir Bencko $^{11}$, Nathaniel Rothman ${ }^{3}$, \\ Paul Brennan ${ }^{1}$, Wong-Ho Chow $^{3}$ and Paolo Boffetta ${ }^{12,13 *}$
}

1 International Agency for Research on Cancer, Lyon, France

${ }^{2}$ Department of Epidemiology, School of Public Health, University of California Los Angeles, Los Angeles, CA, USA

${ }^{3}$ Division of Cancer Epidemiology and Genetics, National Cancer Institute, Bethesda, MD, USA

${ }^{4}$ Samuel Lunenfeld Research Institute of Mount Sinai Hospital, Toronto, ON, Canada

${ }^{5}$ Department of Epidemiology, Institute of Occupational Medicine, Lodz, Poland

${ }^{6}$ Cancer Research Centre, Institute of Carcinogenesis, Moscow, Russia

7 Cancer Research Centre, Department of Epidemiology, Moscow, Russia

8 Institute of Public Health, Bucharest, Romania

${ }^{9}$ Department of Cancer Epidemiology and Genetics, Masaryk Memorial Cancer Institute, Brno, Czech Republic

${ }^{10}$ Department of Preventive Medicine, Faculty of Medicine, Palacky University, Olomouc, Czech Republic

${ }^{11}$ First Faculty of Medicine, Institute of Hygiene and Epidemiology, Charles University in Prague, Prague, Czech Republic

12 International Prevention Research Institute, Lyon, France

${ }^{13}$ Tisch Cancer Institute, Mt. Sinai School of Medicine, New York, NY, USA

Edited by:

Yawei Zhang, Yale University, USA

Reviewed by:

Jie Lin, The University of Texas MD Anderson Cancer Center, USA

Rong Wang, Yale University, USA

*Correspondence:

Paolo Boffetta, The Tisch Cancer Institute, Mount Sinai School of Medicine, One Gustave L. Levy Place, New York, NY 10029, USA. e-mail: paolo.boffetta@mssm.edu
Background: The countries of Central and Eastern Europe have among the highest worldwide rates of renal cell cancer (RCC). Few studies have examined whether genetic variation in xenobiotic metabolic pathway genes may modify risk for this cancer. Methods: The Central and Eastern Europe Renal Cell Cancer study was a hospital-based case-control study conducted between 1998 and 2003 across seven centers in Central and Eastern Europe. Detailed data were collected from 874 cases and 2053 controls on demographics, work history, and occupational exposure to chemical agents. Genes [cytochrome P450 family, $\mathrm{N}$-acetyltransferases, NAD(P)H:quinone oxidoreductase I (NOO1), microsomal epoxide hydrolase $(m E H)$, catechol-O-methyltransferase $(C O M T)$, uridine diphosphateglucuronosyltransferase (UGT)] were selected for the present analysis based on their putative role in xenobiotic metabolism. Haplotypes were calculated using fastPhase. Odds ratios and $95 \%$ confidence intervals were estimated by unconditional logistic regression adjusted for country of residence, age, sex, smoking, alcohol intake, obesity, and hypertension. Results: We observed an increased risk of RCC with one SNP. After adjustment for multiple comparisons it did not remain significant. Neither NAT1 nor NAT2 slow acetylation was associated with disease. Conclusion: We observed no association between this pathway and renal cell cancer.

Keywords: renal cell cancer, epidemiology, NAT1, NAT2, CYP, NOO1, mEH, COMT

\section{INTRODUCTION}

Globally, there are 210,000 cases and 100,000 deaths each year from kidney cancer. The countries of Central and Eastern Europe have among the highest worldwide rates of this disease, particularly the Czech Republic, which has an incidence of 23.6/100,000 among men and 10.9/100,000 among women (Ferlay et al., 2010). The majority ( $>90 \%)$ of adult kidney cancers are renal cell carcinomas (RCC; Eble et al., 2004).

Established risk factors for this cancer include cigarette smoking, hypertension, obesity, and von Hippel-Lindau syndrome, a rare condition caused by alternations or deletions in the VHL gene at chromosome 3p25. Suspected risk factors include diabetes mellitus and acquired cystic kidney disease (Scelo and Brennan, 2007). There is additionally some evidence for an inverse association between RCC risk and physical activity and moderate intake of alcohol (Chow and Devesa, 2008). While not normally considered an occupational cancer, studies have linked RCC to occupational exposure to styrene, gasoline or other petroleum products, asbestos, and organic solvents, particularly trichloroethylene (Mandel et al., 1995; Dosemeci et al., 1999; Bruning et al., 2003; Charbotel et al., 2006; Heck et al., 2010).

The capacity of an individual to activate or transform environmental toxins into less harmful intermediates, and the speed of metabolism, is important for modifying cancer risk. Several reviews have highlighted the genes associated with these processes and their relationship with the development of cancer (Hashibe et al., 2003; Nishikawa et al., 2004). Xenobiotic metabolizing enzymes activate (Phase I) substrates into more 
reactive metabolites (cytochrome P-450 family) or play a detoxifying role (Phase $\mathrm{II}$ ), which reduces the DNA reactivity of genotoxic species and increases excretion $(N$-acetyltransferases, $\mathrm{NAD}(\mathrm{P}) \mathrm{H}$ :quinone oxidoreductase I (NQO1), microsomal epoxide hydrolase $(m E H)$, catechol-O-methyltransferase $(C O M T)$, uridine diphosphate-glucuronosyltransferase $(U G T)$ ). Both the Phase I and Phase II steps in toxin metabolism are influenced by genetic variation, affecting the rate at which carcinogens are metabolized and eliminated.

To date, there is a scarce literature examining polymorphisms in xenobiotic metabolizing genes in relation to RCCs. These studies found varying results, with some finding an association with CYP1A1 (Schulz et al., 1997; Longuemaux et al., 1999; Farker et al., 2000; Semenza et al., 2001; Sasaki et al., 2004; Tanaka et al., 2007; Wiesenhutter et al., 2007; Smits et al., 2008). The purpose of this study was to examine the relationship between occupational exposures, common variation in metabolizing genes and kidney cancer.

\section{MATERIALS AND METHODS STUDY PARTICIPANTS}

A hospital-based case-control study was conducted between 1998 and 2003 across seven centers in Central and Eastern Europe. The study centers were in the Czech Republic (Ceske, Prague, Olomouc, Brno), Poland (Lodz), Romania (Bucharest), and Russia (Moscow). In each center, investigators recruited a series of newly diagnosed cases of primary kidney cancer. Eligibility criteria included histologically confirmed disease (ICD-0-2 code C64) and residence in the study area for at least 1 year. Cases were recruited within 3 months of diagnosis. Additional details on the study have been reported elsewhere (Heck et al., 2010). All tumors underwent central review to confirm histology; the present analysis was limited to RCC.

In all centers, hospital-based controls were chosen among persons admitted to the same hospital as the cases with conditions unrelated to tobacco, including benign disorders, common infections, minor surgical conditions, eye conditions (except cataract or diabetic retinopathy), and common orthopedic diseases (except osteoporosis). No single disease made up greater than $20 \%$ of the control group (diseases of digestive system: 24\%, musculoskeletal system/connective tissue: $12 \%$, genitourinary system: $11 \%$, skin and subcutaneous tissue: $10 \%$, circulatory system: $9 \%$, central nervous system: $9 \%$, eye and ear: $8 \%$, and other smaller categories combined: 17\%). Some controls had been previously recruited from an earlier lung cancer case-control study (Boffetta et al., 2005). Controls were frequency matched to cases by sex, age ( \pm 3 years), center, referral (or of residence) area, and period of recruitment ( \pm 6 months).

Across centers, participation rates ranged from 90 to $99 \%$ among cases and 90 to $96 \%$ among controls. Written informed consent was obtained from all subjects prior to interview. Ethical approval was obtained from relevant review boards.

Trained interviewers administered a standardized questionnaire to participants which elicited information on personal medical history, family history of cancer, tobacco smoking, alcohol drinking, dietary and anthropometric factors, other lifestyle habits, and occupational history. The occupational interview consisted of a general questionnaire for each job, and for 16 prespecified jobs (toolmaker or machinist, motor vehicle mechanic, miner/quarryman, woodworker, painter, welder, insulation worker, meat worker or farmer, and the steel, coke manufacture, foundry, glass, tannery, chemical, and rubber industries) a specific questionnaire was also used. The general questionnaire intended to ascertain complete occupational history and additional information relevant to exposure assessment, including job titles, tasks, industries, starting and stopping dates, full-time/part-time status, working environments, and specific exposures.

The occupational exposure assessment was completed by local experts, including chemists, industrial hygienists, and occupational physicians, who had practical experience in industrial hygiene and took into account regional differences in use of materials, production processes, and prevention measures and changes in exposure patterns within and across jobs and industries over time for the different exposures. We attempted to standardize exposure assessment through yearly workshops and coding exercises. All participating study centers applied the same occupational questionnaires and the same protocol for expert assessment. We assessed inter-rater agreement, finding reasonably good agreement between experts ( $k$ between 0.53 and 0.64; Mannetje et al., 2003). Coders, blinded to case-control status, classified positions using the International Standard Classification of Occupation 1968 version (ISCO-68; International Labour Office, 1969) while industries were coded according to the Statistical Classification of Economic Activities of the European Community, 1999 version (NACE-99; Eurostat, 1999). Main effects results of the occupational analyses have been reported elsewhere (Karami et al., 2008; Heck et al., 2010; Moore et al., 2010; Boffetta et al., 2011).

Blood samples were collected and stored at $-80^{\circ} \mathrm{C}$ prior to genotyping. All subjects in this study provided written informed consent. This study was approved by ethical review boards at the National Cancer Institute, the International Agency for Research on Cancer, and at each participating center.

\section{GENOTYPING}

Genes were selected based on their putative role in xenobiotic metabolism. Genotyping took place at IARC and at the National Cancer Institute's core genotyping facility. Genotyping was done using the $5^{\prime}$ nuclease assay (Taqman, Applied Biosystems) or Illumina GoldenGate ${ }^{\circledR}$ Oligo Pool All (OPA) assay, which was designed using publicly available sequencing information. Laboratory personnel were blinded to case-control status. Sequences of primers and probes were obtained from the SNP500 project (http://snp500cancer.nci.nih.gov/home.cfm). DNA from cases and controls were randomized on PCR plates and duplicate genotyping was performed on a randomly selected $10 \%$ of the samples for quality control. Call rates were similar for cases and controls, and exceeded $94 \%$ for both. All single nucleotide polymorphisms (SNPs) had a genotyping completion rate exceeding 99\%. All duplicate quality control genotypes showed $>99 \%$ concordance. Detailed methods for the genotyping can be found elsewhere (Karami et al., 2008; McKay et al., 2008).

We checked the SNPs included in this analysis against those used in a concurrent genome-wide association study being 
Table 1 | Characteristics of the population.

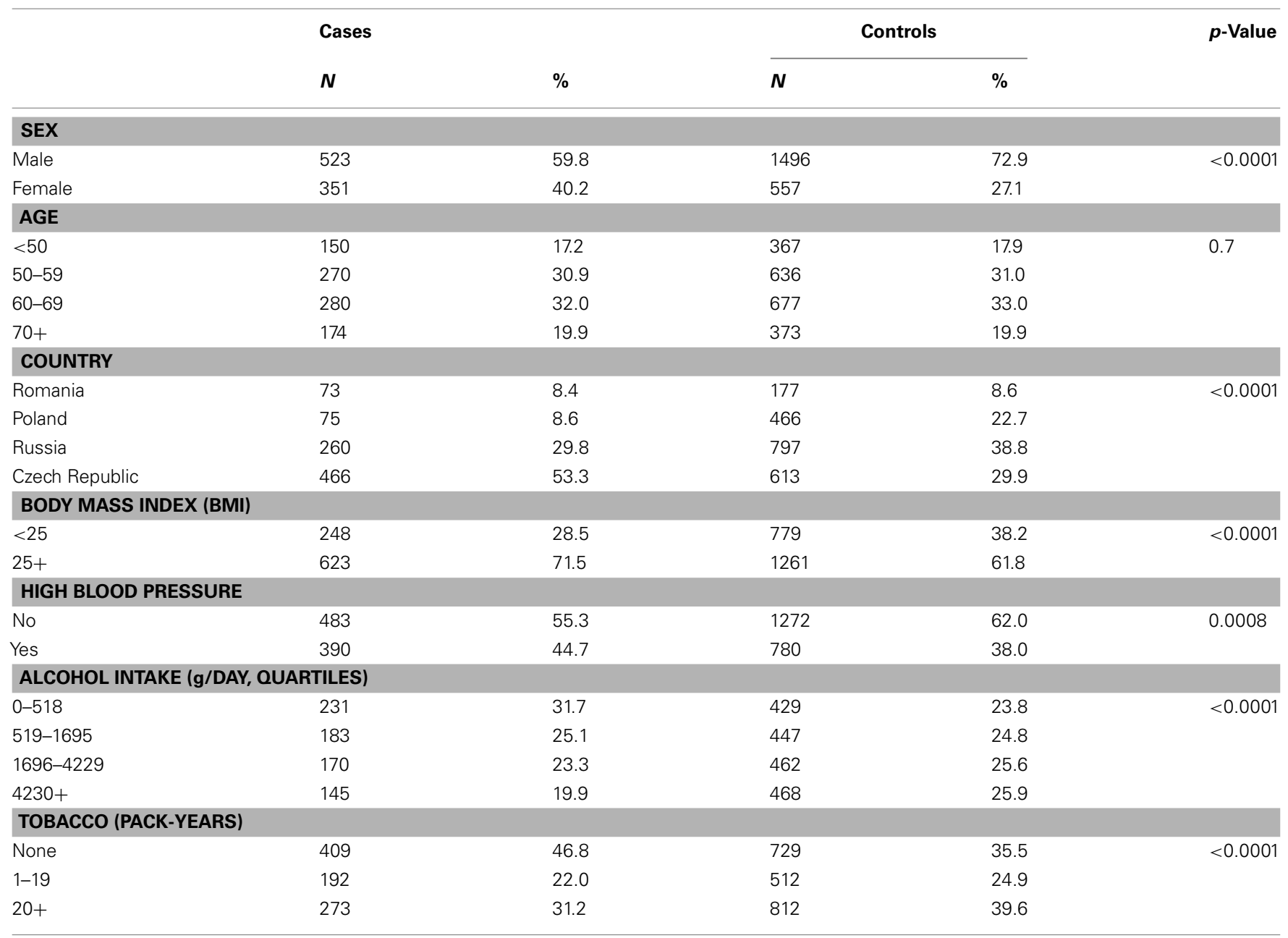

p-Values by chi-square testing.

conducted by our group, which used the Illumina $317 \mathrm{~K}$ chip. Overall we found poor coverage of the genes of interest in this study with SNPs included in our GWAS, with most LD $r^{2}<0.05$. The exception was rs1056836, for which there was an $r^{2}$ of 0.77 with rs162330.

\section{STATISTICAL ANALYSIS}

Each polymorphism was tested in controls to ensure adherence to Hardy-Weinberg equilibrium (Table 2). SNPs exceeding HardyWeinberg equilibrium $(p<0.01)$ were excluded from the present analysis. For each SNP, we calculated odds ratios (OR) and $95 \%$ confidence intervals $(\mathrm{CI})$ using unconditional logistic regression after adjusting for potential confounders including country of residence, age (continuous), sex, blood pressure (high/low or normal), alcohol intake ( $\mathrm{g} /$ day, quartile based upon the distribution in controls), and body mass index $(<25,25+)$. Analyses were conducted with SAS (Cary, NC, USA).

Haplotypes were calculated using fastPhase software (Scheet and Stephens, 2006). The fastPhase haplotypes were then used as covariates in the unconditional logistic regression model. We considered NAT1*10 the highest risk genotype, as has been seen elsewhere, and additionally examined the risk associated with other genotypes (Bell et al., 1995; Cascorbi et al., 2001). Individuals homozygous for rapid NAT2 acetylator alleles $(N A T 2 * 4$, NAT2*11A, NAT2*12A, NAT2*12B, NAT2*12C, NAT2*13) were classified as rapid acetylator phenotype. Those homozygous for slow acetylator alleles were classified as slow acetylator phenotype and heterozygous individuals (one rapid and one slow NAT2 allele) were classified as intermediate acetylator phenotype. We further examined the risk for specific haplotypes. In response to another investigation (Longuemaux et al., 1999), we examined whether any additional risk was conferred among NAT2 slow acetylators who also had rarer variants of CYP1A1.

We conducted an exploratory analysis of exposure to occupational carcinogens among those with selected variants, and checked our findings in a case-only analysis. Stratified analyses were performed by exposure to gasoline, pesticides, and trichloroethylene. Given that tobacco use in some eastern European countries continues to rise (Bosetti et al., 2005; Perlman et al., 2007; Oh et al., 2010), we additionally examined joint effects with tobacco use. 


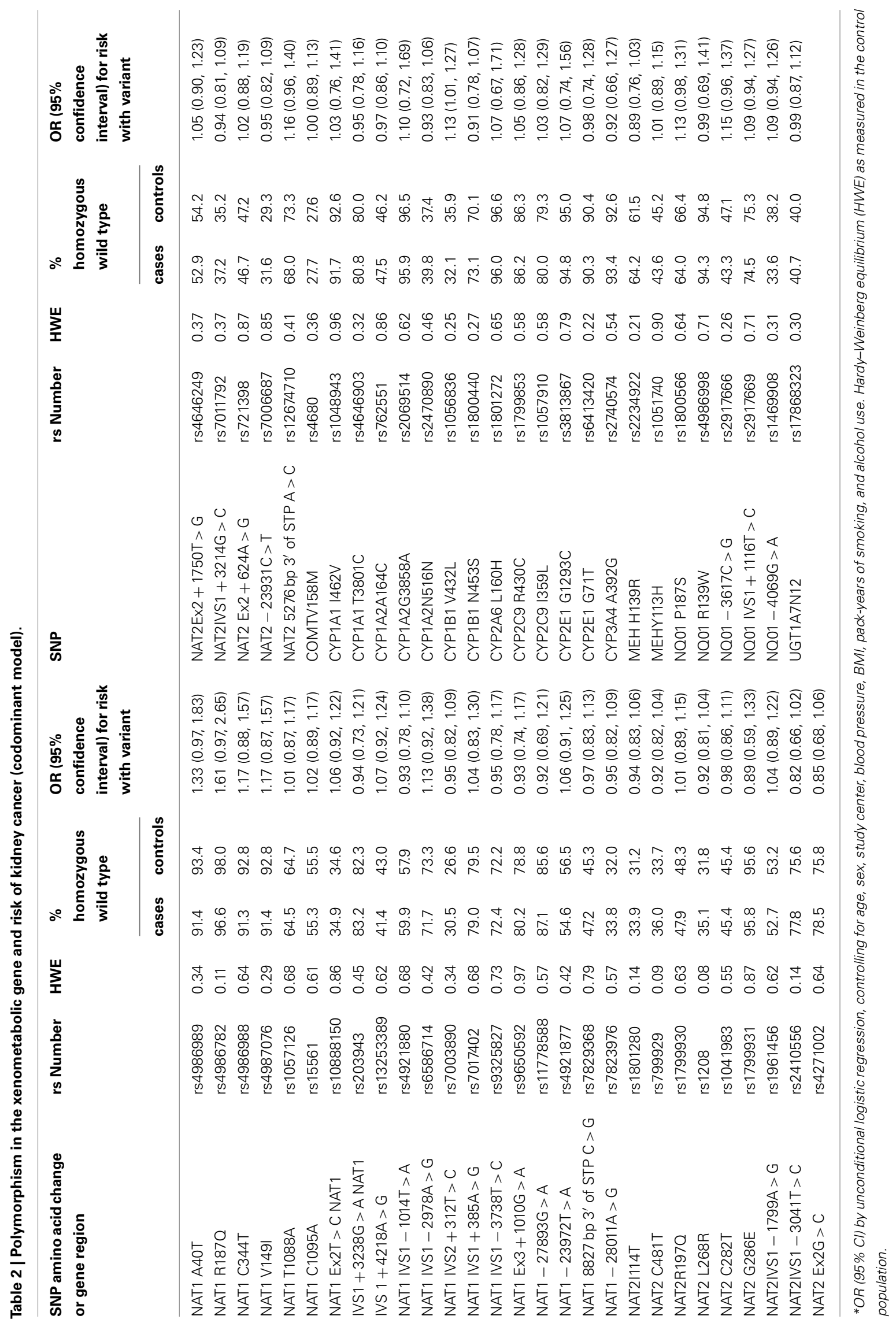


Table 3 | Odds ratios (OR), 95\% confidence intervals (95\% Cl) for the associations of polymorphisms in NAT and renal cell cancer risk.

$\begin{array}{lll}\text { Case } & \text { Control } & \text { OR }(95 \% \mathrm{Cl}) \\ N & N & \end{array}$

\begin{tabular}{llll}
\hline NAT1 & & & \\
Rapid & 572 & 1341 & Referent \\
Intermediate & 253 & 626 & $1.03(0.85,1.26)$ \\
Slow & 30 & 58 & $1.12(0.88,1.43)$ \\
NAT2 & & & \\
Rapid & 54 & 108 & Referent \\
Intermediate & 310 & 731 & $0.76(0.51,1.14)$ \\
Slow & 491 & 1172 & $0.82(0.69,1.01)$
\end{tabular}

OR (95\% Cl) by unconditional logistic regression, controlling for age, sex, study center, high blood pressure, body mass index, pack-years of cigarette smoking, and alcohol intake.

\section{RESULTS}

Of the 954 eligible kidney cancer cases who provided genomic DNA, 80 were excluded due to having histology other than renal cell carcinoma. The 874 cases in the current analysis had clear cell carcinoma $(N=792,90.6 \%)$, papillary $(N=61,7.0 \%)$, chromophobe $(N=19,2.2 \%)$, and two $(<1 \%)$ cases of oncocytic neoplasm.

The population was described in Table 1. The largest proportion of participants was from the Czech Republic. Cases were more likely to be overweight or obese and were more likely to have high blood pressure, in comparison to controls. Controls had greater tobacco use than cases, with the greatest person-years of tobacco use observed in Russia and Poland (data not shown). After elimination of three SNPs that were out of Hardy-Weinberg equilibrium, 56 SNPs remained (Table 2). In the main effects analysis, CYP1B1V432L was associated with RCC risk $(p=0.03)$. Examining this variant, we additionally tested for heterogeneity of results. We did observe different associations by country of residence $(p=<0.0001)$. Results of a random effects model were similar to the fixed effects regression $(\mathrm{OR}=1.13,95 \% \mathrm{CI} 1.01$, 1.27). After adjustment for multiple comparisons via Bonferroni, it did not remain significant.

In haplotype analyses, we did not observe any association between RCC and $N A T 1^{*} 10$ or with NAT2 slow acetylation (Table 3). We were not able to replicate the findings of Longuemaux et al. (1999) who observed additional risk among NAT2 slow acetylators with rarer $C Y P 1 A 1$ variants $(\mathrm{OR}=1.57,95 \% \mathrm{CI}$ $0.96,2.56)$. After stratifying by occupational exposures, we did not observe a greater risk for RCC among NAT1*10 or NAT2 slow acetylators who were tobacco users or occupationally exposed to chemical agents (data not shown), nor did we observe associations when examining risk in the case-only analysis.

\section{DISCUSSION}

To our knowledge, this is the largest study yet conducted of xenometabolic genes in relation to RCC. In this Central and Eastern European population, we observed no clear associations between RCC and genetic variation in the xenometabolic genes. It is likely that if these variants had a true association with disease, we would have observed differing effects between smokers and non-smokers. Although this study's controls had high rates of smoking, making such a differential effect difficult to observe (Heck et al., 2010), we also did not see associations in the case-only analysis.

To our knowledge, there have been two other studies examining NAT2 slow acetylation and RCC. One study $(N$ cases $=115)$ found a strong association between NAT2 genotype and $\mathrm{RCC}(\mathrm{OR}=1.8$; Semenza et al., 2001). The other $(N$ cases $=73$ ) found no independent association with slow acetylator genotype alone $(\mathrm{OR}=1.1)$, although a greater risk was seen among persons who also had certain CYP1A1 variants (Longuemaux et al., 1999). We were not able to replicate these results. Differing findings are likely due to chance.

The CYP $1 B 1^{*} 3$ variant was common, with $47.0 \%$ of total samples heterozygous $\mathrm{C} / \mathrm{G}$ and $18.2 \%$ homozygous $\mathrm{G} / \mathrm{G}$. This genotype is associated with an amino acid substitution from leucine to valine, with higher catalytic activity for Val432 variants than Leu432 variants, potentially causing a differential susceptibility toward tobacco-related cancers. A small study in Japan reported a $50 \%$ increase in RCC among heterozygous $\mathrm{C} / \mathrm{G}$ participants, and an over twofold risk among homozygous G/G participants (Sasaki et al., 2004). This variant has been tested in relation to several other cancers and health conditions. The literature is inconsistent as to whether there is a relationship between this variant and lung cancer (Wenzlaff et al., 2005; Cote et al., 2007; Shah et al., 2008), while no association has been seen with cancers of the ovary or head and neck (Cecchin et al., 2004; Singh et al., 2008).

One study reported higher prevalence of NQO1 variants among RCC patients (Schulz et al., 1997). In our population, there was a marginally greater prevalence among cases of polymorphisms of NQO1 codon $187(p=0.07)$, while the distribution of all other NQO1 SNPs did not differ between cases and controls.

If genetic susceptibility to renal cancer is mediated through metabolic gene polymorphisms, it is possible that combinations of genotypes may be a more meaningful predictor of disease risk than examining single loci genotype, and this study lacked power to do detailed analyses. A strength of the study is the expected genetic homogeneity of the eastern European population, lowering the likelihood of bias from population stratification (Wacholder et al., 2000). Nonetheless, we did observe heterogeneity in the results. Hospital-based controls in our study could potentially cause selection bias if specific genetic variants were related to hospitalization. However, controls with a variety of medical conditions were recruited into the study, lessening the likelihood of such a bias.

In conclusion, no clear associations were observed between RCC and several polymorphisms related to xenobiotic metabolism.

\section{ACKNOWLEDGMENTS}

The authors would like to thank Dr. Beate Ritz for her comments on the manuscript. This work was supported in part by US National Institutes of Health (R01CA092039) and the Intramural Research Program of the US National Institutes of Health, National Cancer Institute, Division of Cancer Epidemiology and Genetics. Julia E. Heck was supported by a grant from the National Cancer Institute (5R25CA087949) and with a special training award from the International Agency for Research on Cancer. 


\section{REFERENCES}

Bell, D. A., Badawi, A. F., Lang, N. P., Ilett, K. F., Kadlubar, F. F., and Hirvonen, A. (1995). Polymorphism in the $N$-acetyltransferase 1 (NAT1) polyadenylation signal: association of NAT $1 * 10$ allele with higher $\mathrm{N}$-acetylation activity in bladder and colon tissue. Cancer Res. 55, 5226-5229.

Boffetta, P., Fontana, L., Stewart, P., Zaridze, D., Szeszenia-Dabrowska, N., Janout, V., Bencko, V., Foretova, L., Jinga, V., Matveev, V., Kollarova, H., Ferro, G., Chow, W. H., Rothman, N., van Bemmel, D., Karami, S., Brennan, P., and Moore, L. E. (2011). Occupational exposure to arsenic, cadmium, chromium, lead and nickel, and renal cell carcinoma: a case-control study from Central and Eastern Europe. Occup. Environ. Med. 68, 723-728.

Boffetta, P., Mannetje, A., Zaridze, D., Szeszenia-Dabrowska, N., Rudnai, P., Lissowska, J., Fabianova, E., Mates, D., Bencko, V., Navratilova, M., Janout, V., Cardis, E., Fevotte, J., Fletcher, T., and Brennan, P. (2005). Occupational X-ray examinations and lung cancer risk. Int. J. Cancer 115, 263-267.

Bosetti, C., Levi, F., Lucchini, F., Negri, E., and Vecchia, C. L. (2005). Lung cancer mortality in European women: recent trends and perspectives. Ann. Oncol. 16, 1597-1604.

Bruning, T., Pesch, B., Wiesenhutter, B., Rabstein, S., Lammert, M., Baumuller, A., and Bolt, H. M. (2003). Renal cell cancer risk and occupational exposure to trichloroethylene: results of a consecutive case-control study in Arnsberg, Germany. Am. J. Ind. Med. 43, 274-285.

Cascorbi, I., Roots, I., and Brockmoller, J. (2001). Association of NAT1 and NAT2 polymorphisms to urinary bladder cancer: significantly reduced risk in subjects with NAT1 $* 10$. Cancer Res. 61, 5051-5056.

Cecchin, E., Russo, A., Campagnutta, E., Martella, L., and Toffoli, G. (2004). Lack of association of CYP $1 \mathrm{~B} 1 * 3$ polymorphism and ovarian cancer in a Caucasian population. Int. J. Biol. Markers 19, 160-163.

Charbotel, B., Fevotte, J., Hours, M., Martin, J. L., and Bergeret, A. (2006). Case-control study on renal cell cancer and occupational exposure to trichloroethylene. Part II: epidemiological aspects. Ann. Occup. Hyg. 50, 777-787.

Chow, W. H., and Devesa, S. S. (2008). Contemporary epidemiology of renal cell cancer. Cancer J. 14, 288-301.
Cote, M. L., Wenzlaff, A. S., Bock, C. H., Land, S. J., Santer, S. K., Schwartz, D. R., and Schwartz, A. G. (2007). Combinations of cytochrome $\mathrm{P}-450$ genotypes and risk of early-onset lung cancer in Caucasians and African Americans: a population-based study. Lung Cancer 55, 255-262.

Dosemeci, M., Cocco, P., and Chow, W. H. (1999). Gender differences in risk of renal cell carcinoma and occupational exposures to chlorinated aliphatic hydrocarbons. Am. J. Ind. Med. 36, 54-59.

Eble, J. N., World Health Organization, and International Agency for Research on Cancer. (2004). Pathology and Genetics of Tumours of the Urinary System and Male Genital Organs. Lyon: IARC Press.

Eurostat. (1999). NACE Rev. 1 - Statistical Classification of Economic Activities in the European Community. Luxembourg: Office for Official Publications of the European Communities.

Farker, K., Lehmann, M. H., Kastner, R., Weber, J., Janitzky, V., Schubert, J., and Hoffmann, A. (2000). Analysis of point mutation in exon 2 of CYP2E1 gene in renal cell/urothelial cancer patients in comparison with control population. Int. J. Clin. Pharmacol. Ther. 38, 30-34.

Ferlay, J., Shin, H. R., Bray, F., Forman, M. R., Mathers, C., and Parkin, D. M. (2010). GLOBOCAN 2008 v1.2, Cancer Incidence and Mortality Worldwide: IARC CancerBase No. 10 [Internet]. Lyon: International Agency for Research on Cancer.

Hashibe, M., Brennan, P., Strange, R. C., Bhisey, R., Cascorbi, I., Lazarus, P., Oude Ophuis, M. B., Benhamou, S., Foulkes, W. D., Katoh, T., Coutelle, C., Romkes, M., Gaspari, L., Taioli, E., and Boffetta, P. (2003). Meta- and pooled-analyses of GSTM1, GSTT1, GSTP1, and CYP1A1 genotypes and risk of head and neck cancer. Cancer Epidemiol. Biomarkers Prev. 12, 1509-1517.

Heck, J. E., Charbotel, B., Moore, L. E., Karami, S., Zaridze, D. G., Matveev, V., Janout, V., Kollarova, H., Foretova, L., Bencko, V., SzeszeniaDabrowska, N., Lissowska, J., Mates, D., Ferro, G., Chow, W. H., Rothman, N., Stewart, P., Brennan, P., and Boffetta, P. (2010). Occupation and renal cell cancer in Central and Eastern Europe. Occup. Environ. Med.67, 47-53.

International Labour Office. (1969). International Standard Classification of Occupations. Geneva: International Labour Office.
Karami, S., Boffetta, P., Rothman, N., Hung, R., Stewart, T., Zaridze, D., Navritalova, M., Mates, D., Janout, V., Kollarova, H., Bencko, V., Szeszenia-Dabrowska, N., Holcatova, I., Mukeria, A., Gromiec, J., Chanock, S., Brennan, P., Chow, W. H., and Moore, L. (2008). Renal cell carcinoma, occupational pesticide exposure, and modification by glutathione $S$-transferase polymorphisms. Carcinogenesis 29 , 1567-1571.

Longuemaux, S., Delomenie, C., Gallou, C., Mejean, A., Vincent-Viry, M., Bouvier, R., Droz, D., Krishnamoorthy, R., Galteau, M. M., Junien, C., Beroud, C., and Dupret, J. M. (1999). Candidate genetic modifiers of individual susceptibility to renal cell carcinoma: a study of polymorphic human xenobioticmetabolizing enzymes. Cancer Res. 59, 2903-2908.

Mandel, J. S., McLaughlin, J. K., Schlehofer, B., Mellemgaard, A., Helmert, U., Lindblad, P., McCredie, M., and Adami, H. O. (1995). International renal-cell cancer study. IV. Occupation. Int. J. Cancer 61, 601-605.

Mannetje, A., Fevotte, J., Fletcher, T., Brennan, P., Legoza, J., Szeremi, M., Paldy, A., Brzeznicki, S., Gromiec, J., Ruxanda-Artenie, C., StanescuDumitru, R., Ivanov, N., Shterengorz, R., Hettychova, L., Krizanova, D., Cassidy, A., van Tongeren, M., and Boffetta, P. (2003). Assessing exposure misclassification by expert assessment in multicenter occupational studies. Epidemiology 14, 585-592.

McKay, J. D., Hashibe, M., Hung, R. J., Wakefield, J., Gaborieau, V., Szeszenia-Dabrowska, N., Zaridze, D., Lissowska, J., Rudnai, P., Fabianova, E., Mates, D., Foretova, L., Janout, V., Bencko, V., Chabrier, A., Hall, J., Boffetta, P., Canzian, F., and Brennan, P. (2008). Sequence variants of NAT1 and NAT2 and other xenometabolic genes and risk of lung and aerodigestive tract cancers in Central Europe. Cancer Epidemiol. Biomarkers Prev. 17, 141-147.

Moore, L. E., Boffetta, P., Karami, S., Brennan, P., Stewart, P. S., Hung, R., Zaridze, D., Matveev, V., Janout, V., Kollarova, H., Bencko, V., Navratilova, M., SzeszeniaDabrowska, N., Mates, D., Gromiec, J., Holcatova, I., Merino, M., Chanock, S., Chow, W. H., and Rothman, N. (2010). Occupational trichloroethylene exposure and renal carcinoma risk: evidence of genetic susceptibility by reductive metabolism gene variants. Cancer Res. 70, 6527-6536.

Nishikawa, A., Mori, Y., Lee, I. S., Tanaka, T., and Hirose, M. (2004). Cigarette smoking, metabolic activation and carcinogenesis. Curr. Drug Metab. 5, 363-373.

Oh, D. L., Heck, J. E., Dresler, C., Allwright, S., Haglund, M., Del Mazo, S. S., Kralikova, E., Stucker, I., Tamang, E., Gritz, E. R., and Hashibe, M. (2010) Determinants of smoking initiation among women in five European countries: a cross-sectional survey. BMC Public Health 10, 74. doi:10.1186/1471-2458-10-74

Perlman, F., Bobak, M., Gilmore, A., and McKee, M. (2007). Trends in the prevalence of smoking in Russia during the transition to a market economy. Tob. Control. 16, 299-305.

Sasaki, M., Tanaka, Y., Okino, S. T., Nomoto, M., Yonezawa, S., Nakagawa, M., Fujimoto, S., Sakuragi, N., and Dahiya, R. (2004). Polymorphisms of the CYP1B1 gene as risk factors for human renal cell cancer. Clin. Cancer Res. 10, 2015-2019.

Scelo, G., and Brennan, P. (2007). The epidemiology of bladder and kidney cancer. Nat. Clin. Pract. Urol. 4, 205-217.

Scheet, P., and Stephens, M. (2006). A fast and flexible statistical model for large-scale population genotype data: applications to inferring missing genotypes and haplotypic phase. Am. J. Hum. Genet. 78, 629-644.

Schulz, W. A., Krummeck, A., Rosinger, I., Eickelmann, P., Neuhaus, C. Ebert, T., Schmitz-Drager, B. J., and Sies, H. (1997). Increased frequency of a null-allele for $\mathrm{NAD}(\mathrm{P}) \mathrm{H}$ : quinone oxidoreductase in patients with urological malignancies. Pharmacogenetics 7, 235-239.

Semenza, J. C., Ziogas, A., Largent, J., Peel, D., and Anton-Culver, H. (2001). Gene-environment interactions in renal cell carcinoma. Am. J. Epidemiol. 153, 851-859.

Shah, P. P., Singh, A. P., Singh, M., Mathur, N., Mishra, B. N., Pant, M. C., and Parmar, D. (2008). Association of functionally important polymorphisms in cytochrome P4501B1 with lung cancer. Mutat. Res. 643, 4-10.

Singh, A. P., Shah, P. P., Mathur, N., Buters, J. T., Pant, M. C., and Parmar, D. (2008). Genetic polymorphisms in cytochrome P4501B1 and susceptibility to head and neck cancer. Mutat. Res. 639, 11-19.

Smits, K. M., Schouten, L. J., van Dijk, B. A., van Houwelingen, K., Hulsbergen-van de Kaa, C. A., 
Kiemeney, L. A., Goldbohm, R. A., Oosterwijk, E., and van den Brandt, P. A. (2008). Polymorphisms in genes related to activation or detoxification of carcinogens might interact with smoking to increase renal cancer risk: results from the Netherlands cohort study on diet and cancer. World J. Urol. 26, 103-110.

Tanaka, Y., Hirata, H., Chen, Z., Kikuno, N., Kawamoto, K., Majid, S., Tokizane, T., Urakami, S., Shiina, H., Nakajima, K., Dhir, R., and Dahiya, R. (2007). Polymorphisms of catechol-O-methyltransferase in men with renal cell cancer. Cancer Epidemiol. Biomarkers Prev. 16, 92-97.

Wacholder, S., Rothman, N., and Caporaso, N. (2000). Population stratification in epidemiologic studies of common genetic variants and cancer: quantification of bias. J. Natl. Cancer Inst. 92, 1151-1158.

Wenzlaff, A. S., Cote, M. L., Bock, C. H., Land, S. J., Santer, S. K., Schwartz, D. R., and Schwartz, A. G. (2005). CYP1A1 and CYP1B1 polymorphisms and risk of lung cancer among never smokers: a population-based study. Carcinogenesis 26, 2207-2212.

Wiesenhutter, B., Selinski, S., Golka, K., Bruning, T., and Bolt, $\mathrm{H}$. M. (2007). Re-assessment of the influence of polymorphisms of phase-II metabolic enzymes on renal cell cancer risk of trichloroethylene-exposed workers.
Int. Arch. Occup. Environ. Health 81, 247-251.

Conflict of Interest Statement: The authors declare that the research was conducted in the absence of any commercial or financial relationships that could be construed as a potential conflict of interest.

Received: 02 November 2011; paper pending published: 14 November 2011; accepted: 31 January 2012; published online: 20 February 2012.

Citation: Heck JE, Moore LE, Lee YCA, McKay JD, Hung RJ, Karami S, Gaborieau V, Szeszenia-Dabrowska $N$, Zaridze DG, Mukeriya A, Mates D, Foretova L, Janout V, Kollárová $H$, Bencko V, Rothman N, Brennan P, Chow W-H and
Boffetta P (2012) Xenobiotic metabolizing gene variants and renal cell cancer: a multicenter study. Front. Oncol. 2:16. doi: 10.3389/fonc.2012.00016

This article was submitted to Frontiers in Cancer Epidemiology and Prevention, a specialty of Frontiers in Oncology.

Copyright (C) 2012 Heck, Moore, Lee, McKay, Hung, Karami, Gaborieau, Szeszenia-Dabrowska, Zaridze, Mukeriya, Mates, Foretova, Janout, Kollárová, Bencko, Rothman, Brennan, Chow and Boffetta. This is an openaccess article distributed under the terms of the Creative Commons Attribution Non Commercial License, which permits non-commercial use, distribution, and reproduction in other forums, provided the original authors and source are credited. 